\title{
Vascular Responses after Alpha Adrenergic Receptor Blockade
}

\section{RESPONSES OF CAPACITANCE AND RESISTANCE VESSELS TO NOREPINEPHRINE IN MAN}

\author{
Francois M. Abboud, Phimlip G. Schmid, and John W. Eckstein \\ From the Cardiovascular Research Laboratories, Department of Internal \\ Medicine, University of Iowa, College of Medicine, Iowa City, Iowa
}

A B S T R A C T Experiments were done to test the hypothesis that alpha receptor blockers antagonize more effectively venous than arterial responses to norepinephrine in man.

Systemic arterial blood pressure, venous pressure in the forearm, blood flow through the forearm, and the volume of the forearm at a venous pressure of $30 \mathrm{~mm} \mathrm{Hg}$ were measured using pressure transducers and a mercury strain-gauge plethysmograph. Infusions of norepinephrine into the brachial artery reduced forearm blood flow and venous distensibility without changing arterial pressure. After intraarterial infusion of phentolamine the decrease in venous distensibility during administration of norepinephrine was blocked almost completely whereas the decrease in blood flow through the forearm was not altered.

The results indicate that alpha adrenergic receptor blockade can antagonize constriction of capacitance vessels more effectively than constriction of resistance vessels.

\section{INTRODUCTION}

High levels of circulating catecholamines and increased sympathetic tone which occur in shock are compensatory mechanisms which are in some re-

\footnotetext{
This work was presented at the 39th Annual Scientific Sessions of the American Heart Association, New York, N. Y., 21 October 1966.

Address requests for reprints to Dr. Francois $\mathrm{M}$. Abboud, Department of Internal Medicine, University of Iowa, College of Medicine, Iowa City, Iowa 52240.

Received for publication 19 May 1967 and in revised form 13 September 1967.
}

spects beneficial (1). The increase in venous resistance and rise in small vein pressure which occur also during adrenergic stimulation may be detrimental because they increase capillary filtration, reduce intravascular volume, and increase hematocrit $(2-5)$. In certain vascular beds $(6,7)$ and particularly in hemorrhagic or endotoxin shock $(8,9)$ venous constriction may be relatively greater than arteriolar constriction during adrenergic stimulation. Since capillary pressure depends to a large extent upon venous pressure and postcapillary resistance (10), a constrictor response of postcapillary vessels which is relatively greater than that of precapillary vessels would result in a net outward movement of capillary fluid $(3,7-10)$. The work of Nickerson indicates that alpha adrenergic receptor blockers that antagonize the vasoconstrictor action of catecholamines reverse the loss of intravascular volume in shock, increase plasma volume, and reduce venous hematocrit more markedly than whole body hematocrit (11).

The foregoing considerations led us to the hypothesis that blockade of alpha receptors causes more complete antagonism of postcapillary venous constriction than of precapillary arterial or arteriolar constriction. Experiments were done to test this hypothesis in man.

\section{METHODS}

11 male subjects, 10 of whom were healthy medical students or colleagues, 22-30 yr old, and one a $59 \mathrm{yr}$ old patient (T.Z.) admitted for evaluation of postural weakness, were studied. They were lying lightly clothed and comfortably supine on a couch. Room temperature was 


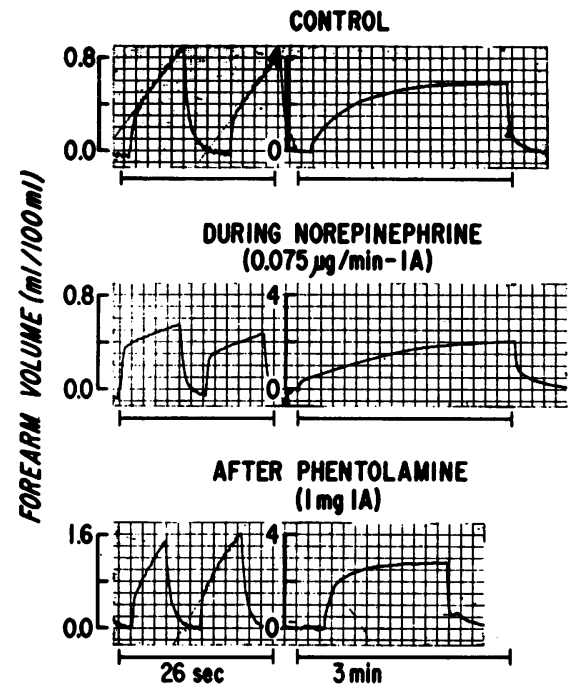

Figure 1 Changes in forearm volume measured with a mercury strain gauge during venous occlusion. The slopes of the first 2 curves in each frame were used to calculate forearm blood flow in milliliters per minute per $100 \mathrm{ml}$ of forearm volume $(12,13)$ and the last curve in each frame was used to calculate venous distensibility.

Norepinephrine decreased forearm blood flow and venous distensibility (middle frame) as compared to control values (upper frame). $5 \mathrm{~min}$ after the the intraarterial infusion of $1.0 \mathrm{mg}$ of phentolamine (lower frame) forearm blood flow had increased to nearly twice the control level but the value for venous distensibility was not higher than the control value.

$82^{\circ} \mathrm{F}$. A polyethylene cannula, (PE 60) 6 inches long and with an outer diameter of $1.2 \mathrm{~mm}$, was introduced a distance of 3 inches into the brachial artery after minimal superficial infiltration of the anticubital area over the artery with $1 \%$ procaine solution. The cannula was connected through stopcocks to a pressure transducer (Statham Instruments, Inc., Los Angeles, Calif., No. P23AA) for arterial pressure measurement and to syringes for infusion of drugs. Another cannula of a similar size was introduced a distance of $2-3$ inches in a retrograde direction into a forearm vein for venous pressure measurements and was connected to another transducer (Statham P23BB) placed approximately at the level of the tip of the cannula.

A strain-gauge plethysmograph compensated for temperature variations (12) was used to measure changes in volume of the forearm (Fig. 1). The strands were made of silastic tubing of $0.4 \mathrm{~mm}$ I.D. and $0.8 \mathrm{~mm}$ 0.D. filled with mercury. The gauge was applied on the arm 2-3 inches distal to the elbow at a tension of $15 \mathrm{~g}$. This tension and small plastic bridges kept the gauge in the same position throughout the period of the experiment. The elbow extended out from the side at about a $60^{\circ}$ angle and was elevated on foam-padded sand bags so that the proximal part of the forearm was approximately 10 $\mathrm{cm}$ above the anterior part of the chest wall. The forearm was slightly flexed and inclined at $45^{\circ}$ to the horizontal plane with the wrist and hand supported by a padded sling. In this position resting or control venous pressure ranged from 0 to $2.5 \mathrm{~mm} \mathrm{Hg}$ (Fig. 2) and in one subject it was $4.0 \mathrm{~mm} \mathrm{Hg}$. This variation in venous pressure probably reflects slight variation in placement of the pressure gauge with reference to the tip of the venous cannula or on rare occasions the position of the tip of the cannula in a small or deep vein with a relatively high venous pressure. Wood has reported the pressure in veins of the forearm to be $0.5 \mathrm{~cm}$ of saline when the forearm is raised 10 or more $\mathrm{cm}$ above heart level (13). From this low level of venous pressure the veins could be distended freely when venous congestion was produced (Figs. 1 and 2). In one subject (P.S.) a water-filled plethysmograph was used to measure changes in forearm volume. All measurements were recorded on a direct writing oscillograph (Sanborn Co., Waltham, Mass.).

A pneumatic cuff was placed around the distal part of the forearm and inflated to suprasystolic pressures during the measurements. This cuff arrested the circulation to the hand and excluded the contribution of the venous return from the hand to changes in volume of the forearm. A second pneumatic cuff was placed around the arm proximal to the plethysmograph for venous occlusion. Changes in forearm volume produced by sudden inflation of the venous occlusion cuff were used to measure both the rate of blood flow and venous distensibility in the same segment of forearm $(12,13)$.

During measurements of forearm blood flow the speed of the recorder was set at $2.5 \mathrm{~mm} / \mathrm{sec}$ and the sensitivity of the systems used to record venous pressure and forearm volume was increased to obtain optimal curves during the short periods of venous occlusion. The rise in venous pressure during occlusion was small and the cuff pressure which ranged from 15 to $20 \mathrm{~mm} \mathrm{Hg}$ was applied intermittently for periods of $6-10 \mathrm{sec}$ (Figs. 1 and 2).

During measurements of venous distensibility the speed of the recorder and the sensitivity of the systems used to record venous pressure and forearm volume were reduced (Figs. 1 and 2). The venous occlusion cuff was inflated suddenly to produce a rise in venous pressure to $30 \mathrm{~mm}$ $\mathrm{Hg}$. Pressure was then held constant for a period of 1.5-3 min until forearm volume became stable or was increasing at only a negligible rate. The forearm volume at a venous pressure of $30 \mathrm{~mm} \mathrm{Hg}$ is reported as the value for venous distensibility.

The effects of intraarterial infusions of norepinephrine on forearm blood flow and venous distensibility were measured before and after intraarterial infusions of phentolamine. During the infusion of phentolamine we observed in some experiments a transient increase in base line volume which we attributed to the initial surge of blood into the veins as flow increased suddenly (Fig. 2, lower half). A similarly transient increase in volume had been seen in previous experiments during infusions of isoproterenol (14). During infusions of norepinephrine 

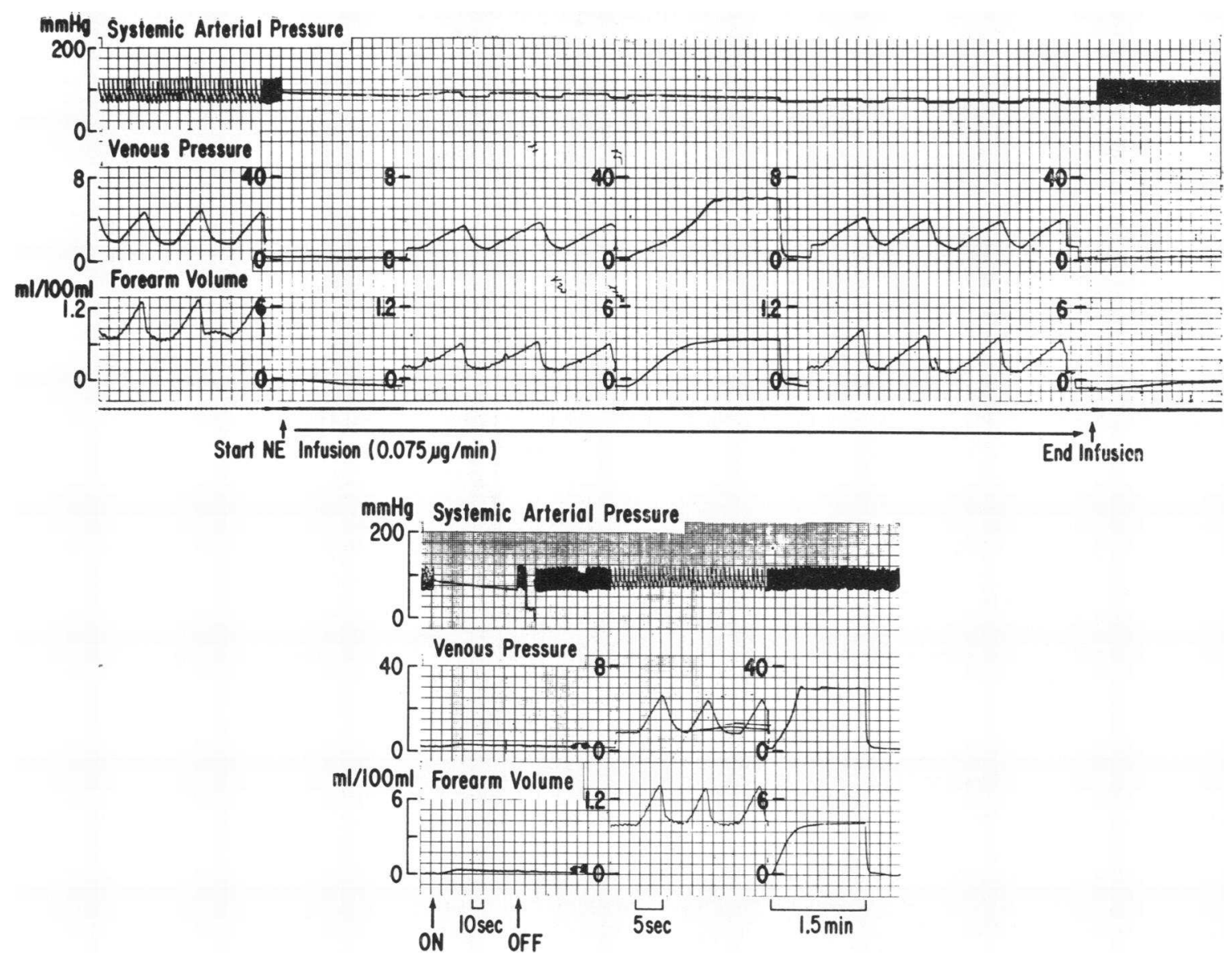

FIGURE 2 Changes in systemic arterial pressure, venous pressure, and forearm volume before, during, and after the intraarterial infusion of norepinephrine (upper half) and an intraarterial infusion of phentolamine (lower half). The infusion of norepinephrine was given after $0.5 \mathrm{mg}$ of phentolamine had been infused intraarterially. Arterial pressure was not affected by norepinephrine and phentolamine. The decrease in base line volume shown here during infusion of norepinephrine was the largest seen in any of the 11 experiments. It was accompanied by a slight decrease in venous pressure. After the end of infusion the base line volume returned to exactly the same level as before infusion. During the infusion of phentolamine (indicated by on and off arrows) there was only a transient increase in base line volume which returned promptly to control levels.

there was usually a slight reduction in base line volume which did not return to the original level until the infusion was stopped (Fig. 2, upper half). This effect was occasionally associated with a minimal decrease in venous pressure; it was greater with the higher dose of norepinephrine and occurred also during administration of norepinephrine after phentolamine but to a lesser degree. The reductions in base line volume regardless of their possible causes (13) amounted to only a few tenths of a milliliter and were seen also when the water plethysmograph was used in subject P.S. and in previous experiments (15). No correction was made for the small downward shift in base line volume, and forearm volume at a venous pressure of $30 \mathrm{~mm} \mathrm{Hg}$ was measured always with reference to the control or resting volume obtained before the infusion was started. Had we corrected for this shift in base line, our values for venous distensibility would have been approximately $10 \%$ higher on the average but our conclusions would not be altered (Table II). Increases in base line volume were never observed during infusions of norepinephrine.

After the subjects had achieved a stable resting state experimental observations were begun. Sets of observations included a $1 \mathrm{~min}$ period for measurement of blood flow, and a 1.5-3 min period for measurement of venous distensibility followed by another $1 \mathrm{~min}$ period for measurement of flow. These observations were made before the infusion of norepinephrine, $2 \mathrm{~min}$ after starting a $7 \mathrm{~min}$ intraarterial infusion of $0.075 \mu \mathrm{g}$ of norepinephrine per min, and again $2 \mathrm{~min}$ after starting another $7 \mathrm{~min}$ infusion of $0.15 \mu \mathrm{g}$ of norepinephrine per min. A $10-15$ min rest period was allowed between sets of observations. 
TABLE I

Forearm Blood Flow in Response to Norepinephrine into the Brachial Artery before and after Phentolanine*

\begin{tabular}{|c|c|c|c|c|c|c|c|c|c|}
\hline \multirow[b]{2}{*}{ Subject } & \multicolumn{3}{|c|}{ Before phentolamine } & \multicolumn{3}{|c|}{ After $0.5 \mathrm{mg}$ of phentolamine } & \multicolumn{3}{|c|}{ After $1.0 \mathrm{mg}$ of whentolaminc } \\
\hline & C & $\mathrm{NE}_{1}$ & $\mathrm{NE}_{2}$ & c & $\mathrm{NE}_{\mathbf{1}}$ & $\mathrm{NE}_{2}$ & C & $\mathrm{NE}_{1}$ & $\mathrm{NE}_{2}$ \\
\hline & \multicolumn{3}{|c|}{$\mathrm{ml} / 100 \mathrm{ml} / \mathrm{min}$} & \multicolumn{3}{|c|}{$\mathrm{mi} / 100 \mathrm{ml} / \mathrm{min}$} & \multicolumn{3}{|c|}{$\mathrm{ml} / 100 \mathrm{ml} / \mathrm{min}$} \\
\hline B. $\mathrm{H}$. & 5.4 & 2.2 & 1.8 & & & & 10.0 & 7.0 & 5.4 \\
\hline S. M. & 4.5 & 2.0 & 1.9 & & & & 8.0 & 5.2 & 5.4 \\
\hline T. $Z$. & 9.9 & 3.2 & 2.8 & & & & 18.0 & 13.1 & 10.7 \\
\hline P.S. & 7.4 & 4.8 & 3.5 & 17.8 & 8.2 & 6.9 & & & \\
\hline T. P. & 3.8 & 3.0 & 2.7 & 8.1 & 5.5 & 4.4 & 12.0 & 8.1 & 6.5 \\
\hline T. R. & 6.4 & 2.6 & 2.3 & 7.9 & 4.5 & 4.0 & 13.0 & 8.5 & 8.5 \\
\hline S. J. & 6.8 & 3.8 & 3.6 & 7.3 & 4.9 & 4.0 & 10.9 & 6.8 & 6.1 \\
\hline P. P. & 4.4 & 1.8 & 1.6 & 7.3 & 2.9 & 2.4 & 10.9 & 7.3 & 7.3 \\
\hline D. J. & 3.7 & 2.9 & 2.5 & 4.7 & 4.1 & 3.6 & 7.8 & 5.6 & 6.1 \\
\hline F. W. & 4.7 & 3.4 & 3.2 & 6.5 & 5.1 & 5.0 & 13.7 & 8.6 & 7.3 \\
\hline E. S. & 8.5 & 2.8 & 2.6 & 14.6 & 10.7 & 5.9 & 13.7 & 8.6 & 7.3 \\
\hline Mean & 5.95 & 2.95 & 2.59 & 9.28 & 5.74 & 4.52 & 11.19 & 7.67 & 6.99 \\
\hline \multicolumn{10}{|c|}{$\begin{array}{l}\text { Mean of individ- } \\
\text { ual differences }\end{array}$} \\
\hline $\begin{array}{l}\mathrm{SE} \\
P \S\end{array}$ & \multicolumn{2}{|c|}{0.58} & & \multicolumn{2}{|c|}{$\begin{array}{r}0.97 \\
>0.05\end{array}$} & $\begin{array}{l}20 \\
05\end{array}$ & \multicolumn{2}{|c|}{$\begin{array}{r}0.40 \\
>0.05\end{array}$} & $\begin{array}{r}0.61 \\
>0.05\end{array}$ \\
\hline
\end{tabular}

* C refers to control observations. Each of the 2 doses of phentolamine caused a significant increase in control blood flow over that seen before phentolamine $(P<0.05) . \quad \mathrm{NE}_{1}$ and $\mathrm{NE}_{2}$ refer to the doses of norepinephrine; 0.075 and 0.15 $\mu \mathrm{g} / \mathrm{min}$ respectively.

† The mean decreases in blood flow caused by NE were in all cases significantly different from $0(P<0.05)$.

$\$ P$ values refer to significance of difference between reductions in flow caused by NE after phentolamine and reductions in flow caused by the same doses of NE before phentolamine. Statistical comparisons were made with paired $t$ test analyses and supported by an analysis of variance (Table IV).

These three sets of observations were repeated a few minutes after the intraarterial infusion of $0.5 \mathrm{mg}$ of phentolamine and again after $1.0 \mathrm{mg}$ of phentolamine

The dose of norepinephrine is given in terms of the base of $l$-norepinephrine bitartrate which was diluted in $5 \%$ glucose in water and infused at rates of 1.2 and 2.4 $\mathrm{ml} / \mathrm{min}$. No measurable changes in forearm blood flow or venous distensibility were observed when $5 \%$ glucose was infused into the brachial artery at these rates (14). Phentolamine methanesulfonate was infused usually in 2 and $4 \mathrm{ml}$ of distilled water over a period of 1.5-2 min.

\section{RESULTS}

Infusions of norepinephrine and of phentolamine into the brachial artery had no detectable systemic effects; brachial arterial pressure and heart rate did not change significantly (Fig. 2).

Forearm blood flow. At constant arterial pressure, changes in forearm blood flow reflect changes in forearm vascular resistance. Before phentolamine the two doses of norepinephrine caused a decrease in flow indicating constriction of resistance vessels. The lower dose caused a smaller decrease in flow (Table I). There was a positive correlation between resting flow before the administration of norepinephrine and the magnitude of decrease in flow during norepinephrine (Fig. 3).

After phentolamine forearm blood flow increased significantly and remained elevated at a level nearly twice the control level (Table I). Decreases in flow during norepinephrine after phentolamine were similar to decreases observed before phentolamine, which indicated that significant constriction of resistance vessels persisted.

Venous distensibility. At a constant venous pressure of $30 \mathrm{~mm} \mathrm{Hg}$ changes in forearm volume reflect changes in venous distensibility. Before phentolamine the two doses of norepinephrine decreased venous distensibility ; the lower dose caused a smaller response (Table II).

After phentolamine and before norepinephrine venous distensibility did not change significantly 
TABLE II

Venous Distensibility of the Forearm in Response to Norepinephrine into the Brachial Artery before and after Phentolamine*

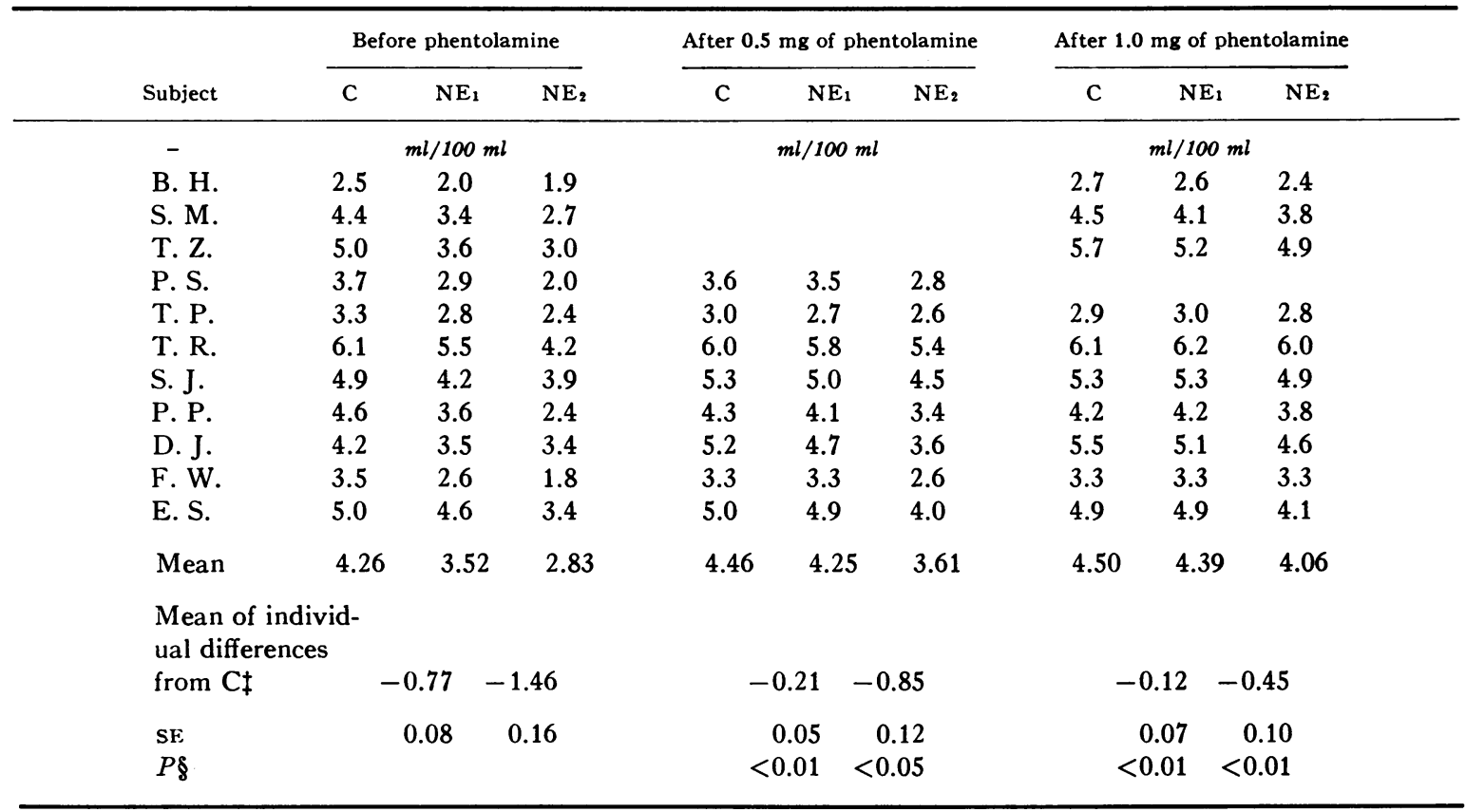

* For abbreviations and symbols see footnote to Table I. Values for venous distensibility represent the volume of forearm at a venous pressure of $30 \mathrm{~mm} \mathrm{Hg}$. Phentolamine did not change control values (C) of venous distensibility $(P>0.05)$.

$\ddagger$ All mean responses to $\mathrm{NE}$ were significantly different from $0(P<0.05)$ except the response to $\mathrm{NE}_{1}$ after $1.0 \mathrm{mg}$ of phentolamine $(P>0.05)$.

$\S$ See footnote $\S$ to Table I.

(Table II) at a time when resting forearm blood flow had nearly doubled (Table I). Venous responses to norepinephrine were reduced markedly after $0.5 \mathrm{mg}$ of phentolamine and were nearly abolished after $1.0 \mathrm{mg}$.

\section{DISCUSSION}

The results obtained in the present experiments indicate that after phentolamine the constrictor effect of norepinephrine on capacitance vessels in the forearm of man was nearly completely antagonized whereas the resistance vessels of the same segment of forearm still constricted actively in response to norepinephrine. Actually the absolute reductions in forearm flow and increases in forearm vascular resistance caused by norepinephrine were not altered significantly by the two doses of phentolamine (Table II and Fig. 3). This does not mean, however, that the alpha blocker had no effect on resistance vessels. In fact, phentolamine caused a dilatation of resistance vessels, doubling forearm blood flow at the same arterial pressure. At high levels of resting blood flow the constrictor effect of norepinephrine on resistance vessels is expected to be greater than at low levels of flow; this was evident from the positive correlation between resting flow and the decrease in flow during norepinephrine after phentolamine (Fig. 3 ). The absence of a greater response after phentolamine indicates that the alpha blocker must have antagonized in part the constrictor effect of norepinephrine on resistance vessels. The blockade, however, was much less effective in resistance than in capacitance vessels. Responses of resistance vessels represent primarily arterial responses and responses of capacitance vessels are predominantly venous responses.

Another estimate of venous responses is the ratio of the rate of rise in venous pressure to the rate of increase in volume of forearm obtained simul- 


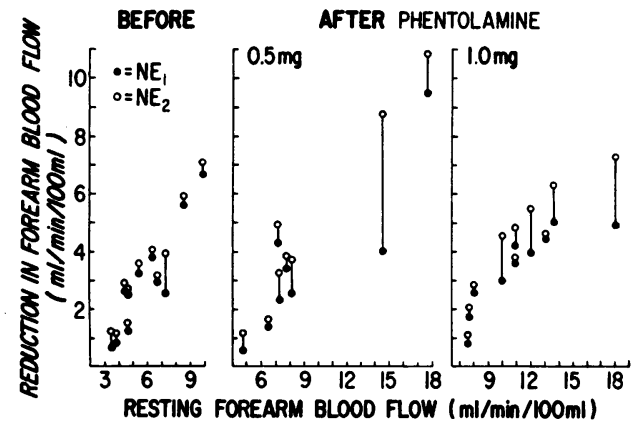

FIGURE 3 Relationship between resting forearm blood flow and the decrease in blood flow in response to norepinephrine $(N E)$ before and after phentolamine. A positive correlation exists between resting flow and decrease in flow during $\mathrm{NE}$ before before and after phentolamine. Calculation of the degree of relationship between resting flow and decrease in flow in response to $\mathrm{NE}_{2}(0.15 \mu \mathrm{g} /$ min) gave the following correlation coefficients: $r=0.91$ $(P<0.01)$ before phentolamine, $r=0.88(P<0.05)$ after $0.5 \mathrm{mg}$ of phentolamine, and $r=0.89(P<0.01)$ after $1.0 \mathrm{mg}$ of phentolamine. Note that after $1.0 \mathrm{mg}$ of phentolamine the levels of resting flow were higher but the decreases in flow during $\mathrm{NE}$ were in the same range as those seen before phentolamine.

taneously during sudden inflation of the venous occlusion cuff. This ratio has been described by Sharpey-Schafer as an index of venous tone (16).
Because of the limitations of this technique which were described by Wood (13), by Bevegård and Shepherd (17), and by Brown, Goei, Greenfield, and Plassaras (18) we did not use it to measure quantitative changes in venous distensibility. We did however calculate the ratios. In doing so we were able to compare $(\Delta \mathrm{P} / \Delta \mathrm{t}) /(\Delta \mathrm{V} / \Delta \mathrm{t})$ to corresponding values of venous distensibility obtained by sustained congestion of the forearm (Tables II and III). The problems reported by others concerning $(\Delta \mathrm{P} / \Delta \mathrm{t}) /(\Delta \mathrm{V} / \Delta \mathrm{t})$ became apparent during the calculations. A nonlinear rise in venous pressure prevented us from obtaining a ratio in 3 of the 11 experiments. In many of the remaining experiments several tracings were discarded before selecting the ones showing good linear rises in pressure. There was marked variability in the ratio not only from subject to subject but also in the same subject during short experimental periods when there were no interventions. On the other hand, measurements of forearm volume at a sustained venous pressure of $30 \mathrm{~mm} \mathrm{Hg}$ give remarkably similar results at the beginning and at the end of a study $2 \mathrm{hr}$ later. It has been suggested (13, $17)$ that the variability in $(\Delta \mathrm{P} / \Delta \mathrm{t}) /(\Delta \mathrm{V} / \Delta \mathrm{t})$ may reflect uneven rates of increase in forearm volume

TABLE III

Change in Ratio of Rate of Rise in Forearm Venous Pressure $(\Delta P / \Delta t)$ and Volume $(\Delta V / \Delta t)$ in Response to Norepinephrine into the Brachial Artery before and after Phentolamine*

\begin{tabular}{|c|c|c|c|c|c|c|c|c|c|}
\hline \multirow[b]{2}{*}{ Subject } & \multicolumn{3}{|c|}{ Before phentolamine } & \multicolumn{3}{|c|}{ After $0.5 \mathrm{mg}$ of phentolamine } & \multicolumn{3}{|c|}{ After $1.0 \mathrm{mg}$ of phentolamine } \\
\hline & C & $\Delta \mathrm{NE}_{1}$ & $\Delta \mathrm{NE}_{2}$ & C & $\Delta \mathrm{NE}_{1}$ & $\Delta \mathrm{NE}_{2}$ & C & $\Delta \mathrm{NE}_{1}$ & $\Delta \mathrm{NE}_{2}$ \\
\hline & \multicolumn{3}{|c|}{$m m \mathrm{Hg} / \mathrm{ml}$ fer $100 \mathrm{ml}$} & \multicolumn{3}{|c|}{$m m \mathrm{Hg} / \mathrm{ml}$ per $100 \mathrm{ml}$} & \multicolumn{3}{|c|}{$\mathrm{mm} \mathrm{Hg} / \mathrm{ml}$ per $100 \mathrm{ml}$} \\
\hline B. $\mathrm{H}$. & 9.2 & +8.2 & +8.2 & & & & 7.4 & 0.0 & +5.9 \\
\hline S. M. & 10.0 & +0.6 & +0.8 & & & & 6.2 & -0.5 & +0.2 \\
\hline T. P. & 8.3 & +1.3 & +8.5 & 15.7 & +1.8 & +4.4 & 17.4 & 0.0 & 0.0 \\
\hline T. R. & 3.2 & +3.4 & +2.5 & 1.4 & +2.7 & +3.4 & 3.1 & +0.9 & -0.2 \\
\hline S. J. & 5.4 & +0.7 & +3.4 & 4.2 & 0.0 & +1.6 & 3.5 & +0.5 & +1.1 \\
\hline P. P. & 5.0 & +2.0 & +4.6 & 6.5 & +0.2 & 0.0 & 5.3 & -2.1 & -4.2 \\
\hline D. J. & 10.8 & +2.2 & +3.0 & 6.8 & +4.2 & +9.4 & 6.2 & +1.0 & +3.0 \\
\hline F. W. & 4.0 & +2.6 & +12.9 & 3.4 & +1.8 & +3.6 & 4.1 & +0.7 & +1.6 \\
\hline Mean $\ddagger$ & 7.0 & +2.6 & +4.5 & 6.3 & +1.8 & +3.7 & 6.6 & +0.06 & +0.8 \\
\hline SE & & 0.86 & 1.42 & & 0.64 & 1.31 & & 0.35 & 1.02 \\
\hline$P \delta$ & & & & & $>0.05$ & $>0.05$ & & $<0.01$ & $<0.01$ \\
\hline
\end{tabular}

* $\mathrm{C}$ refers to control observations. $\Delta \mathrm{NE}_{1}$ and $\Delta \mathrm{NE}_{2}$ represent the changes in $(\Delta \mathrm{P} / \Delta \mathrm{t}) /(\Delta \mathrm{V} / \Delta \mathrm{t})$ during infusions of norepinephrine as compared to $\mathrm{C}$.

$\ddagger$ The increases in ratios during infusions of $\mathrm{NE}_{1}$ and $\mathrm{NE}_{2}$ after $1.0 \mathrm{mg}$ of phentolamine were not significantly different from $0(P>0.05)$ at a time when significant reduction in flow took place (see Table $\mathrm{I}$ ).

$\S P$ values refer to significance of difference between changes in $(\Delta \mathrm{P} / \Delta \mathrm{t}) /(\Delta \mathrm{V} / \Delta \mathrm{t})$ caused by norepinephrine after phentolamine and changes in the ratio caused by the same dose of norepinephrine before phentolamine. 
TABLE IV

Analysis of Variance of Responses [Flow, Venous Distensibility and $(\Delta P / \Delta t) / \Delta V / \Delta t)]$

to Norepinephrine before and after Phentolamine*

\begin{tabular}{|c|c|c|c|c|c|c|c|c|c|}
\hline \multirow[b]{2}{*}{ Source of variation } & \multicolumn{3}{|c|}{$\begin{array}{l}\text { Changes in forearm } \\
\text { blood flow } \\
\text { (Table I) }\end{array}$} & \multicolumn{3}{|c|}{$\begin{array}{l}\text { Changes in venous } \\
\text { distensibility } \\
\text { (Table II) }\end{array}$} & \multicolumn{3}{|c|}{$\begin{array}{c}\text { Changes in } \frac{\Delta \mathrm{P} / \Delta \mathrm{t}}{\Delta \mathrm{V} / \Delta \mathrm{t}} \\
\text { (Table III) }\end{array}$} \\
\hline & df & $\begin{array}{c}\text { Mean } \\
\text { square }\end{array}$ & F & df & $\begin{array}{l}\text { Mean } \\
\text { square }\end{array}$ & F & df & $\begin{array}{l}\text { Mean } \\
\text { square }\end{array}$ & F \\
\hline Subject & 6 & 19.1 & $9.5 \ddagger$ & 6 & 0.16 & 1.5 & 5 & 13.1 & 2.6 \\
\hline Blocker§ & 2 & 3.5 & 1.8 & 2 & 2.61 & $25.6 \ddagger$ & 2 & 43.8 & $8.7 \ddagger$ \\
\hline \multicolumn{10}{|l|}{ Dose } \\
\hline (norepinephrine) & 1 & 3.9 & 1.9 & 1 & 3.54 & $34.7 \ddagger$ & 1 & 33.5 & $6.6 t$ \\
\hline Blocker $X$ dose & 2 & 0.9 & 0.5 & 2 & 0.15 & 1.5 & 2 & 9.9 & 1.9 \\
\hline Error & 30 & 2.0 & & 30 & 0.10 & & 25 & 5.0 & \\
\hline
\end{tabular}

* Analysis of variance was done on responses of subjects in whom the two doses of agonist and the two doses of antagonist were used. In the paired $t$ test analysis all responses were included.

$\ddagger$ Indicate $P<0.01$. The results of the analysis would support the conclusion that phentolamine (Blocker) altered the effect of norepinephrine on venous distensibility (Table II) and $(\Delta \mathrm{P} / \Delta \mathrm{t}) /(\Delta \mathrm{V} / \Delta \mathrm{t}$ ) (Table III) but it did not alter the effect on blood flow through the forearm (Table I).

8 "Blocker" refers to variation among responses to norepinephrine before phentolamine, after $0.5 \mathrm{mg}$ and after 1.0 $\mathrm{mg}$ of phentolamine.

during rapid congestion and unequal increases in pressure in different veins where the rate of filling may differ markedly. Comparison of results in Tables II and III indicates that $(\Delta \mathrm{P} / \Delta \mathrm{t}) /(\Delta \mathrm{V} / \Delta \mathrm{t})$ gave us, in these experiments, results which were in general qualitatively similar to those obtained by slow sustained venous congestion at a constant pressure. This method however does not provide quantitatively accurate estimates of venous distensibility. In some instances even qualitative accuracy may be missing. In two of six subjects (D.J. and T.R.) the response to the high dose of norepinephrine after $0.5 \mathrm{mg}$ of phentolamine was greater than before phentolamine:

After the intraarterial infusion of phentolamine forearm blood flow had increased to nearly twice the control level but the value for venous distensibility was not higher than the control value. This finding supports the notion that in comfortable subjects lying supine in a warm environment the sympatho-adrenal influence on venous distensibility is negligible. This does not appear to be true however for resistance vessels.

The same dose of norepinephrine was infused into the brachial artery before and after phentolamine but the concentration of norepinephrine in the blood stream may have differed after phentolamine because of two factors. The increased blood flow after the blocker would tend to decrease the concentration of norepinephrine but the blockade of receptor sites would tend to increase the concentration. In experiments reported in a subsequent paper on the perfused forelinb of the dog these two factors appeared to cancel each other (19).

The implications of the venous and arterial responses reported here as far as the effect of alpha receptor blockers on capillary pressure and capillary filtration remain speculative. The degree to which the changes in distensibility of capacitance vessels can be related to changes in venous or postcapillary resistance has not been ascertained in man. Several observations suggest that such a relationship exists. Mellander and Lewis (8) and Shadle, Zukof, and Diana (4) have shown that during sympathetic nerve stimulation a decrease in distensibility of capacitance vessels is associated with an increase in capillary filtration in hincllimbs of cats and dogs. Marked increases in pressure have been observed in the metacarpal veins in man during infusions of norepinephrine; these veins are large enough to contribute significantly to the volume of the limb as capacitance vessels. In experiments on the perfused forelimb of the dog (19) increases in pressure in small veins and increases in venous resistance to flow in response to injections of norepinephrine and to sympathetic stimulation were blocked effectively with an alpha receptor 
blocker and the results on venous and arterial resistances paralleled those reported here on capacitance and resistance vessels in man. We have reported also that the effects of intraarterial administration of isoproterenol on capacitance and resistance vessels in the forearm of man (14) were similar to the effects on venous and arterial resistances respectively in the perfused forelimb of $\operatorname{dog}(20)$.

Mellander and Lewis (8) reported that the vasoconstrictor response to sympathetic stimulation and to norepinephrine in the skeletal muscle of cat was abolished earlier in resistance vessels than in capacitance vessels as a result of hemorrhagic shock. The preservation of a constrictor response of postcapillary vessels beyond that of precapillary vessels was associated with a significant loss of intravascular volume by excessive capillary filtration. Hinshaw, Vick, Jordan, and Wittmers (21) also reported greater venous than arterial constriction in response to norepinephrine or epinephrine in the perfused foreleg and Hinshaw and Nelson (9) described similar responses in the perfused loop of small intestine of dog with the development of irreversible endotoxin shock. Nickerson and Gourzis (2) reported also that the administration of phenoxybenzamine to dogs can induce a prompt increase in plasma volume, a reduction in plasma protein, and a fall in hematocrit of femoral vein blood which was more marked than the fall in whole body hematocrit. These effects indicate a reduction in capillary filtration. These observations and the results of the present experiments lead us to speculate that alpha receptor blockade represents a most effective means of opposing capillary filtration in the presence of an adrenergic stimulus such as is seen in shock. Both the complete blockade of venous constriction and the preservation of some arterial constriction would contribute to the reduction in capillary filtration $(3,10)$. On the other hand a vasodilator drug such as isoproterenol which dilates arterial or precapillary resistance vessels without reducing significantly venous resistance $(14,20)$ may theoretically increase capillary filtration (10).

\section{ACKNOWLEDGMENTS}

This work was supported by research grants from the American Heart Association and the U. S. Public Health Service (HE-09835 and HE-02644), and by Research
Career Program Awards HE-K3-17013 and HE-K64626 from the National Heart Institute.

\section{REFERENCES}

1. Neil, E. 1962. Reflex mechanisms and the central nervous system. In Shock: Pathogenesis and Therapy; an international symposium. K. D. Bock, editor. Springer-Verlag, Berlin. 172.

2. Nickerson, M., and J. T. Gourzis. 1962. Blockade of sympathetic vasoconstriction in the treatment of shock. J. Trauma. 2: 399.

3. Haddy, F. J., J. I. Molnar, and R. W. Campleell. 1961. Effects of denervation and vasoactive agents on vascular pressures and weight of $\operatorname{dog}$ forelimb. $A m$. J. Physiol. 201 : 631.

4. Shadle, O. W., M. Zukof, and J. Diana. 1958. Translocation of blood from the isolated dog's hindlimb during levarterenol infusion and sciatic nerve stimulation. Circulation Res. 6: 326.

5. Freeman, N. E. 1933. Decrease in blood volume after prolonged hyperactivity of the sympathetic nervous system. Am. J. Physiol. 103: 185.

6. Abboud, F. M., and J. W. Eckstein. 1966. Comparative changes in segmental vascular resistance in re sponse to nerve stimulation and to norepinephrinc. Circulation Res. 18: 263.

7. Davis, D. L. 1963. Effect of sympathetic stimulation on dog paw volume. Am. J. Physiol. 205: 989.

8. Mellander, S., and D. H. Lewis. 1963. Fffect of hemorrhagic shock on the reactivity of resistance and capacitance vessels and on capillary filtration transfer in cat skeletal muscle. Circulation Res. 13: 105.

9. Hinshaw, L. B., and D. L. Nelson. 1962. Venous response of intestine to endotoxin. Am. J. Physiol. 203: 870 .

10. Pappenheimer, J. R., and A. Soto-Rivera. 1948. Effective osmotic pressure of the plasma proteins and other quantities associated with the capillary circulation in the hindlimbs of cats and dogs. Am. J. Physiol. 152: 471.

11. Nickerson, M. 1963. Sympathetic blockade in the therapy of shock. Am. J. Cardiol. 12: 619.

12. Whitney, R. J. 1953. The measurement of volume changes in human limbs. J. Phy'siol. (London). 121: 1.

13. Wood, J. E. 1965. The veins; normal and abnormal function. Little, Brown \& Co. Inc., Boston. 3-30 and 71-76.

14. Eckstein, J. W., M. G. Wendling, and F. M. Abhoud. 1965. Forearm venous responses to stimulation of adrenergic receptors. J. Clin. Invest. 44: 1151.

15. Eckstein, J. W., and W. K. Hamilton. 1957. The pressure-volume responses of human forearm veins during epinephrine and norepinephrine infusions. $J$. Clin. Invest. 36: 1663.

16. Sharpey-Schafer, E. P. 1961. Venous tone. Brit. Mcd. J. 2: 1589 .

17. Bevegard, B. S., and J. T. Shepherd. 1965. Effect of local exercise of forearm muscles on forearm capacitance vessels. J. Appl. Physiol. 20: 968. 
18. Brown, E., J. S. Goei, A. D. M. Greenfield, and G. C. Plassaras. 1963. Distensibility of the low pressure vesscls of the forearm. Fedcration Proc. 22: 344. (Abstr.)

1\%. Abboud, F. M., and J. W. Eckstein. 1968. Vascular responses after alpha adrenergic receptor blockade. II responses of venous and arterial segments to adrenergic stimulation in the forelimb of dog. J. Clin. Invest. 47: 10 .
20. Abboud, F. M., J. W. Eckstein, and B. G. Zimmerman. 1965. Venous and arterial responses to stimulation of beta adrenergic receptors. Am. J. Physiol. 209 : 383.

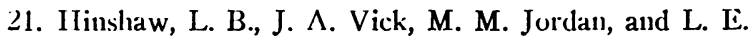
Wittmers. 1962. Vascular changes associated with the development of irreversible endotoxin shock. Am. J. Physiol. 202: 103. 